Council also approved the establishment of a Commission on Physicochemical Symbols, Units, and Terminology and a Commission on Isotopic Abundances and Atomic Weights. These Commissions will continue the work of current Commissions with new and expanded responsibilities. Both were formed only after careful study by special committees, which reported to the Bureau on the desirability of continuing this work at the Commission level.

\section{Ohtaki to Head New Membership Development Committee}

An ad hoc Membership Development Committee [MDC] was established by the Executive Committee at the conclusion of the General Assembly. The MDC will encourage expansion in the Membership of the Union by undertaking and coordinating activities aimed at soliciting new National Adhering
Organizations and Associate National Adhering Organizations.

Prof. Hitoshi Ohtaki (Japan) has been named by President Alan Hayes to chair the new committee. As a member of the IUPAC Bureau and Executive Committee, Prof. Ohtaki has been particularly concerned about potential expansion of the Union in Asia and will now coordinate aggressive efforts to develop IUPAC's global character. The other members of the Committee are Prof. Berhanu Abegaz (Botswana), Prof. Robert G. Gilbert (Australia), and Dr. John Malin (USA).

\section{Chemistry International to Get New Look}

A redesigned Chemistry International $(C I)$, the IUPAC news magazine, will appear in the coming months under a program approved by the Bureau. (See President's Report on the State of the Union, p. 133.)

\title{
President's Report on the State of the Union
}

This article is an abridged version of the President's State of the Union report presented by IUPAC President Dr. Alan Hayes at the $41^{\text {st }}$ IUPAC Council meeting on 7-8 July 2001 in Brisbane, Australia.

\section{Introduction}

The two years since our last General Assembly have been very active for IUPAC. The approval by the Council at Berlin of the reorganization of the management of IUPAC's scientific work, changing the Union's scientific structure from one based on permanent commissions to one based on projects, has led to changes in the responsibilities of the Division Presidents and Division Committees, and the establishment and implementation of project approval and evaluation processes.

We have implemented two new programs that were also approved by Council at Berlin - the IUPAC Prize for Young Chemists and the support of conferences in developing and economically disadvantaged countries. Both programs address important needs and provide high visibility to IUPAC.

We have undertaken comprehensive reviews of the Union's activities in three important areas: systematic chemical nomenclature, chemistry education, and interaction with the chemical and pharmaceutical industry. We are now prepared to recommend organizational changes and strategies for pursuing future work in these areas.

The Union's regular activities in contributing to the language and scientific-industrial framework of chemistry continued with the publication in 2000 of 21 recommendations and reports in our official
Journal, Pure and Applied Chemistry (PAC), publication of 3 books, and the publication of two special issues of $P A C$, one on the topic of "Nanostructured Materials", the other on "Green Chemistry". In dissemination of information, the bimonthly newsmagazine Chemistry International $(C I)$ highlights current activities and general policy issues, and the informal IUPAC $e$-News provides timely updates. The IUPAC web site continues to be a major source of information for members of IUPAC bodies. It is also becoming the public face of IUPAC and is regularly accessed for information about all aspects of chemistry by scientists and students worldwide. A strategy for $C I$ has been developed that will better integrate these three approaches and improve the readability of $C I$.

For the first time, IUPAC has published its Biennial Report using the goals of the Strategic Plan and in an attractive format. We have also recently developed an information brochure with particular emphasis on the Union's interactions with industry.

The report that follows is intended to highlight activities and actions that are important to the Union as a whole. Please see the complete text of my State of the Union Report and the individual reports of the Division Presidents and Standing Committee Chairmen, available online, for details not included in this summary.

\section{The Strategic Plan}

The IUPAC Strategic Plan, adopted initially in 1998, is intended to be reviewed biennially and revised as needed. The 2000-2001 Strategic Plan included only 


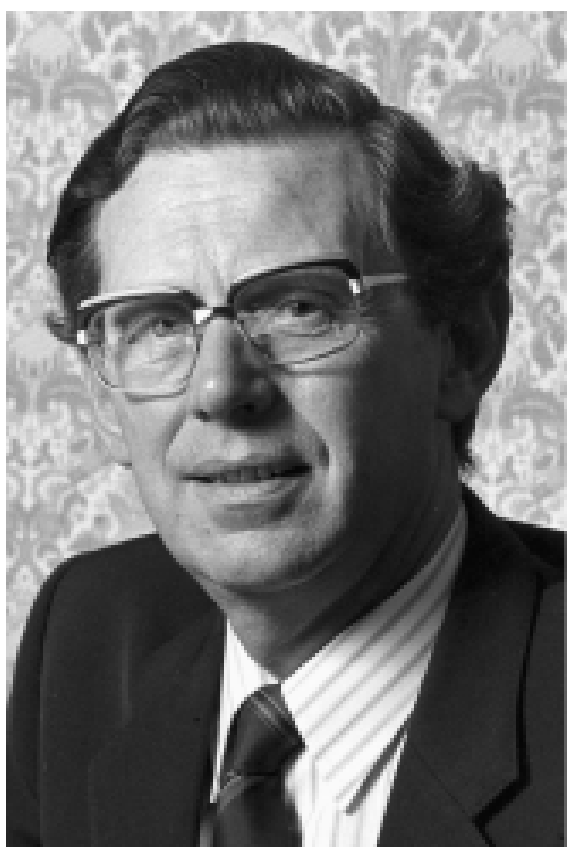

Dr. Alan Hayes

a small number of changes in Strategic Thrusts to update it. The next revision of the Strategic Plan is expected to be more significant.

To facilitate the revision process, I have appointed a small ad hoc committee, chaired by Dr. Edwin P. Przybylowicz, with membership drawn from IUPAC bodies and other chemists interested in IUPAC and with broad geographic representation. The Executive Committee has scheduled a special session for the end of 2001 to consider the revised Strategic Plan and other strategic issues and to prepare a final version of the Strategic Plan for approval by the Bureau. The goal of the meeting will be to bring more focus to the work of the Union and to ensure that the Union does what is wanted and what it can best do. It is expected that by considering the revised Strategic Plan, as proposed by the ad hoc Committee, and other inputs, such as those from NAOs, the Executive Committee will be able to decide on a set of actions to continue moving the Union forward.

\section{Changes in Organization and Management of IUPAC's Scientific Work}

Council approved at Berlin a policy and an operational program based on the conceptual framework that the Union represents and which serves the entire world chemistry community. The objective is to improve quality, relevance, international impact, and effectiveness of the Union's scientific work. The integrated program has required major changes in the responsibilities of the Division Presidents and Division Committees, in the election procedures on the Division level, and in project approval.
One of the major objectives of the new program is to solicit ideas for IUPAC projects from the worldwide chemistry community and to set up short-term Task Groups to carry out the projects, with membership open to the entire community. In line with this objective, representatives of the Division Committees met during the General Assembly to share experience on soliciting project proposals from the wider global chemical community. Emphasis will continue to be placed in the coming biennium on this outreach effort.

\section{IUPAC Congresses}

The recently completed Congress in Brisbane has joined the last two Congresses, in Geneva and Berlin, as a successful scientific conference. I extend deep thanks and appreciation to the Royal Australian Chemical Institute (RACI), its Board, President, National Director, and enthusiastic staff for the superb organization of the Congress, and to the International Advisory Board and its Chairman, Prof. Y. T. Lee, for shaping the outstanding scientific program. The $39^{\text {th }}$ IUPAC Congress will be held in Ottawa, Canada in 2003.

\section{Nomenclature}

Nomenclature is an activity that for many chemists defines IUPAC. It has been important for the past 80 years and will continue to be important in the future. As part of the reorganization of IUPAC work, it was felt that this area required special care and attention.

In recognition of both IUPAC's long-standing interest in this subject and the need for planning the continued development of this complex and somewhat esoteric subject, the Officers, at Berlin, accepted the Secretary General's proposal to develop a long-range strategy by initially convening a meeting of nomenclature experts and broad categories of users of chemical nomenclature. Secretary General Dr. Edwin D. Becker and Dr. Alan D. McNaught (Royal Society of Chemistry), who has been active on the Commission on Nomenclature of Organic Chemistry (CNOC), the Interdivisional Committee on Nomenclature and Symbols (IDCNS), and the Committee on Printed and Electronic Publications (CPEP), organized a Strategy Roundtable on Representations of Molecular Structure: Nomenclature and Its Alternatives.

The group assembled for this meeting represented experts in organic, inorganic, biochemical, and macromolecular nomenclature; users of nomenclature in academia and industry; the patent, international trade, and health and safety communities; journal editors and publishers; database providers; and software vendors-a total of 41 participants from ten 
countries. Following wide-ranging discussions during the first day, on the second day, a number of recommendations to IUPAC were considered. As a result of this meeting, the Bureau recommended to Council that a new Division of Systematic Nomenclature and Structure Representation be formed. Council has approved this recommendation.

This effort is an example of the new IUPAC way of doing things. First, the customers are asked what they need and how can IUPAC best contribute to meeting that need. Next, the question is asked, should IUPAC be doing this? Finally, a program or project is developed that addresses the expressed needs of the chemistry community and that involves both people who have been active in IUPAC previously and others who have not.

\section{Education}

The central issue of science education in general, and education in chemistry in particular, pertains to the preservation and advancement of global human capital. Meaningful contributions to this endeavor constitute a major challenge for the Union. IUPAC, as an international worldwide organization, must consider in this context the diversity of cultural approaches and the different conditions and needs in distant parts of the world. It should be emphasized that chemistry, owing to its interdisciplinary nature, provides the basis for scientific training in the natural sciences.

The problems facing the global chemistry education system involve the erosion of scope and quality of science education, resulting in science illiteracy in the developed countries and the need for qualified scientific manpower in less-developed countries. At the General Assembly in 1999, Prof. Joshua Jortner assumed responsibility for organizing an ad hoc IUPAC Education Strategy Development Committee (ESDC). Prof. Peter W. Atkins, who is internationally known in the field of chemical education, was recruited to be the Chairman of the ESDC. Following two meetings, the ESDC concluded its task by preparing a report that puts forth recommendations for possible future directions of IUPAC's activities in chemistry education and the public appreciation of chemistry. I would like to express my appreciation of the work done by Prof. Atkins and the members of the Committee. They have provided a report that will lead to major changes in the ways IUPAC responds to the needs of the global chemistry community in this important area. (The report of the ESDC is available on the IUPAC Web site.)

The proposals by the ESDC now provide a framework for developing an overall strategy by which IUPAC can contribute to chemistry education in a way that complements the programs of national chemistry organizations. A special Working Party of the Executive Committee has evaluated the recommendations of the ESDC for feasibility and implementation. The recommendations of the Working Party have been adopted by the Bureau and will be implemented by the end of the year (see IUPAC Web site).

\section{IUPAC-Industry Relations}

In 1999, the Bureau appointed an ad hoc Committee on IUPAC-Industry Relations. The members of this Committee were industrial scientists, from both IUPAC and outside, with myself as Chairman. As a result of the recommendations of this group, the Committee on Chemistry and Industry (COCI) will be reorganized to serve as a better communications forum for industry with IUPAC. COCI, with its revised Terms of Reference and membership, will work to increase the participation of industrial scientists in IUPAC's work and to improve communications with the global chemical industry

As part of my personal contribution to this effort, I have met with the heads of a number of regional and global chemical trade associations. These meetings have led, I believe, to a greater appreciation of IUPAC's work by these groups.

As Vice President, I proposed in my Critical Assessment that we should attempt to combine existing meetings of chemical society presidents and the heads of regional chemistry federations and also invite the participation of leaders of industry and chemical trade associations in a World Chemistry Leadership Meeting (WCLM). I am pleased to report that the first WCLM took place on Monday, 9 July, immediately after the IUPAC General Assembly, and addressed a number of issues of concern to the assembled chemical societies and leaders of chemical industry.

\section{World Chemistry Leadership Meeting}

On Monday, 9 July, a World Chemistry Leadership Meeting (WCLM) was held. There were 37 participants from 25 countries, including presidents of chemical societies, regional chemical federations, industry trade associations, representatives of developing countries, and the IUPAC officers. The two half-day meetings addressed two sets of issues. The morning session was devoted to the single topic of "Sharing Responsibility for Our ScienceChemistry Across National Boundaries". IUPAC was requested to address this subject by a resolution of the meeting of chemical 
society presidents held in Berlin during the IUPAC General Assembly and Congress in 1999. This session addressed how the chemical societies of the developed countries plan, using the resources available to them, to work with chemists and chemical societies in developing and economically disadvantaged countries, to strengthen chemistry in those countries, and to assist in their development. The afternoon session considered subjects of common interest to the assembled chemical societies and other representatives of the worldwide chemistry community. Most of the session was devoted to a discussion of what various chemical societies and trade federations are doing to improve the public perception of chemistry and how to improve communication among the societies and thereby share information and successful ideas.

At the Berlin meeting of chemical society presidents, organized by the Gesellschaft Deutscher Chemiker, IUPAC was requested to organize a meeting on the topic "Sharing Responsibility for Our Science-Chemistry Across National Boundaries" in order to provide a forum for examining ways that chemistry can be strengthened in developing and economically disadvantaged countries. The entire morning session of the WCLM was devoted to this subject.

\section{IUPAC's Publications}

Based on an analysis of the future of the scientific publishing market, the Committee on Printed and Electronic Publications recommended, and the Executive Committee approved, the change of PAC from having an official publisher to being published by IUPAC. The driving force for this change was the desire to achieve greater independence in how the Union approaches electronic publishing. The financial analysis indicated that there was little financial risk in this change. This change was made with the January 2000 issue of $P A C$, and the results have met our expectations, both in terms of the improved quality of the journal and improved financial results.

As a consequence of the severing of our relationship with Blackwell Science, we purchased the stock of IUPAC books published by Blackwell. The Secretariat has been selling these books directly since the middle of 2000.

In April 2000, the Executive Committee appointed an ad hoc Committee to study the overall strategy of the Union with regard to its news magazine, Chemistry International $(C I)$. This committee, called the Chemistry International Strategy Development Committee, Chairman Dr. D. H. M. Bowen, former chair of CPEP, presented its final report to the Executive Committee in April 2001. The report can be summarized by saying that $C I$ needs a better look and feel. It should be seen as a news magazine that reports on IUPAC activities, as well as issues in chemistry of international interest, rather than a collection of reports from IUPAC bodies. The CISDC report emphasizes the importance of integrating the three main news channels of the Union-CI, the Web site, and $e$-News. The Executive Director was asked to prepare an implementation plan with associated costs. This plan was reviewed at the recent Bureau meeting and adopted.

\section{Dissemination of Information}

The IUPAC web site (http://www.iupac.org) has been greatly expanded over the biennium. The number of visitors to the site has increased from fewer than 3000 in March 1998 to almost 200000 in January 2001. Six mirror sites are currently active: the RSC in the United Kingdom, SUNSite Germany, SUNSite South Africa, the Korean Chemical Society, SUNSite Japan, and the Institut Teknologi Bandung in Indonesia.

A significant addition to the Union's communication with not only the active and former participants in IUPAC activities, but with interested people worldwide, is $e$-News. Since it was first e-mailed on 28 June 2000, five $e$-News editions have been dispatched to the pool of current members, including NAOs, Associate NAOs, Associated Organizations, and Company Associates. Positive feedback has been received regarding the value of this electronic newsletter as a means of communicating with our members.

\section{Service of Chemistry}

The CHEMRAWN series continues to address issues at the interface of science and society. A highly successful CHEMRAWN Conference on Green Chemistry was held on 9-13 June 2001 in Boulder, Colorado, USA.

At the Berlin Council meeting, a new initiative to encourage career development of young scientists was approved. The IUPAC Prize for Young Chemists, based on their doctoral research, will be awarded annually, with the winners being brought to the IUPAC Congress to receive their prizes and to participate in the scientific activities. The nine prize winners for 2000-2001 received their prizes at the opening ceremonies in Brisbane on Sunday, 1 July. Each prize winner also presented his/her work in a 
poster at the Congress.

The first Goal in our Strategic Plan addresses IUPAC's responsibility "to serve as a scientific, international, nongovernmental body in objectively addressing global issues involving the chemical sciences". Within recent months, IUPAC has been asked to take on just this type of task for the Organization for the Prohibition of Chemical Weapons (OPCW), the international body set up to administer the Chemical Weapons Convention (CWC), now ratified by 143 countries, which is designed to "determine for the sake of all mankind to exclude completely the possibility of the use of chemical weapons". I believe that this activity is important for the image of chemistry and for international public policy, and I expect that the Union will be able to provide the necessary leadership and objective advice.

\section{IUPAC Activities in Less-Developed Countries}

A new initiative to promote sponsorship of IUPAC conferences in developing and economically disadvantaged countries was approved by Council at Berlin. This initiative provides funds to help IUPAC member countries that often cannot hold major international conferences to do so. Holding an international conference is an excellent way to help scientists in developing countries maintain the contacts that are a necessary part of participating at a high level in modern chemistry. It also enables young scientists to participate in a major international conference, an opportunity many of them rarely receive.

\section{Globalization}

IUPAC currently has 44 National Adhering Organizations, which include the vast majority of the world's most developed chemistry economies. Yet, there are a significant number of countries that are major contributors to the chemical sciences and to chemical industry but which do not currently adhere to IUPAC. In all our contacts with international chemistry federations and societies, we are continually exploring ways by which such countries can be brought into the IUPAC family. Indeed, as we broaden the scope of the Union's programs, we must make it clear why these countries will benefit from membership in IUPAC.

Overall, our message to the world's chemists is one of openness. We are restructuring our scientific programs to permit any scientist anywhere in the world to propose projects that will benefit international science. We have made it easier for top-notch scientists in countries that currently do not adhere to IUPAC to participate in the Union's projects and to serve on its scientific bodies. We have made it clear through our Strategic Plan and through our followup actions that IUPAC believes in the service of chemistry to society, worldwide. We are making strenuous efforts to work cooperatively with the chemical and pharmaceutical industries to provide an independent scientific base that will assist them in bringing the benefits of chemistry to mankind. I believe that IUPAC's new and candid approach to the world chemistry community will pay dividends in years ahead, both to the Union and to the science that we serve.

\section{Epilogue}

In his report to the Berlin Council meeting, President Jortner stated six points that he described as the future message of IUPAC:

- openness to the fast expansion of the borders of the chemical sciences

- response to conceptual and structural changes in chemical research and technology

- perpetuation of interdisciplinary unification, high quality, relevance, and the global dimension in activities

- contribution to the globalization of the scientific endeavor

- adherence to the principles, norms, values, and ethics of science

- recruiting "human capital" for IUPAC

IUPAC has embarked on a new course for the future. The changes that have been made and that will take full effect starting in 2002 are intended to address these six points. IUPAC can only remain important to chemists by continuing to meet their needs for an organization that helps them do their work. We must continue to ask the two fundamental questions:

- Why should IUPAC be involved with this activity?

- What does the customer need/want? 